\title{
The Effect of Personality on EPL Self-Efficacy and Outcome Expectations among
} Graduates in Nigerian Universities

\author{
Adeola Samuel Adebusuyi ${ }^{\star \rtimes}$ \\ Olubusayo Foluso Adebusuyi ${ }^{2}$ \\ 'Department of Psychology, Nigeria Police Academy, Wudil Kano, Nigeria. \\ Email:adedejiadebusuyi@gmail.com Tel: +2348066121838 \\ ${ }^{2}$ PhD Student of the Department of Science and Technology Education, Obafemi Awolowo University, Ile-Ife, \\ Nigeria. \\ Email:oadebusuyi@pg-student.oauife.edu.ng
}

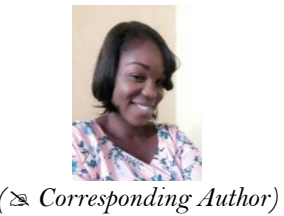

\begin{abstract}
The study tests the big five personality traits on entrepreneurial, professional and leadership (EPL) self-efficacies, job and entrepreneurial outcome expectation. It also examined the influence of these efficacies on their corresponding outcome expectations. The study design was crosssectional and used a sample of 363 new graduates from Nigeria's tertiary institutions. We used a regression path analysis to determine the causal model tested in this study. Results showed that extraversion, openness and agreeableness significantly lead to concurrently high EPL selfefficacies, neuroticism inversely related to professional and leadership self-efficacies, but conscientiousness did not relate with any of the self-efficacies. Second, agreeableness, neuroticism, and conscientiousness led to job and entrepreneurial outcome expectations. Third, only leadership self-efficacy led to both job and entrepreneurial outcome expectations. These findings deepen our understanding of how entrepreneurial, professional and career mindset can be achieved in an individual.
\end{abstract}

Keywords: Entrepreneurial, Professional, Leadership, Self-efficacy, Outcome expectations, Personality trait

Citation | Adeola Samuel Adebusuyi; Olubusayo Foluso Adebusuyi (2020). The Effect of Personality on EPL Self-Efficacy and Outcome Expectations among Graduates in Nigerian Universities. Asian Journal of Social Sciences and Management Studies, 7(4): 265-270. History:

Received: 10 June 2020

Revised: 20 July 2020

Accepted: 24 August 2020

Published: 16 September 2020

Licensed: This work is licensed under a Creative Commons Attribution 3.0 License (cc))

Publisher: Asian Online Journal Publishing Group
Acknowledgement: Both authors contributed to the conception and design of the study.

Funding: This study received no specific financial support

Competing Interests: The authors declare that they have no conflict of interests.

Transparency: The authors confirm that the manuscript is an honest, accurate, and transparent account of the study was reported; that no vital features of the study have been omitted; and that any discrepancies from the features of the study have been omitted
study as planned have been explained.

study as planned have been explained.
Ethical: This study follows all ethical practices during writing.

\section{Contents}

1. Introduction.

2. Theoretical Frameworks and Literature Review

3. Methods 


\section{Contribution of this paper to the literature}

This paper showed the role of the big-five personality in the development of career adaptability.

\section{Introduction}

Nowadays, given the changing and unpredictable world of work, scholars and governments are in agreement about graduates' ability to adapt to other areas outside of their primary field of study. To achieve this, entrepreneurship education was introduced into school curricula at all levels of education. Governments also have introduced several programmes to stimulate entrepreneurial interest among the youths. Despite all that has been done, school graduates remain attached to the traditional career of white-collar jobs (Sinclair, 2008). The reason for this, according to Frese, Gielnik, and Mensmann (2016) is that government programmes to facilitate entrepreneurship, without proper consideration of the psychological sides will lead to failure of such programmes.

The psychological aspects of adapting to different career paths have attracted theoretical and empirical attention from scholars. Prominent theorists such as Savickas (2013) have shed light on this crucial topic. Further theoretical explanations came from Lent and Brown (2013) called the social cognitive model of career selfmanagement (CSM). CSM is a process theory of adaptive career behaviour across the life span. Another theoretical explanation is from Chan et al. (2012). They introduced a theory that showed that people could subjectively be concurrently high on entrepreneurship, leadership and professional (EPL) career motivation, self-efficacy and intention. The main thrust of this theory is that graduates should be simultaneously high on EPL career mindset in order not to be stranded when they enter the labour market. However, their theory did not discuss the predictors of this framework. The purpose of this study, therefore, is to investigate the antecedent of one of their theoretical construct - i.e. EPL self-efficacy. We did this by integrating the Chan et al.'s EPL framework with Lent and Brown's CSM framework.

\section{Theoretical Frameworks and Literature Review}

\subsection{Social Cognitive Theory of Career Self-Management (CSM)}

The CSM is a process theory proposed by Lent and Brown (2013). It is an updated version of the social cognitive career theory (SCCT) of Lent, Brown, and Hackett (1994). Whereas SCCT is a content theory of how people arrive at a particular career choice, the CSM is a process theory of the different activities people engage in to manage, cope, adjust to changes etc. concerning various phases of career life throughout the lifetime. It is a theory that emphasizes proactively influencing to things to work in one's favour, rather than passively waiting for an opportunity to come. For instance, a graduate should not wait for an advert to be placed before sending applications to the organizations of his choice. The theory is not assuming that all the power to change things is in the hands of the actors; it just argues that a substantial ability to change things is in the hands of the actors.

\subsection{The Entrepreneurship, Professionalism, Leadership (EPL) Career Framework}

The EPL framework by Chan et al. (2012) is a specific strategy that actors can use during the process of career entry, especially after graduating from school. It argues that graduates should be not only professional minded but also entrepreneurial and leadership inclined. This is because being a professional is limiting, and the times we live in require people to be able to adapt to different changes as they come. A professionally-minded graduate may find himself stranded in an environment where there is a high rate of unemployment. Surviving in such an environment requires being entrepreneurially inclined since entrepreneurship as been seen as a panacea for unemployment. Furthermore, even in an organization, a professional who suddenly finds himself in a managerial position has to know how to lead people to achieve organizational goals. Thus, the theory proposes that individuals have to be concurrently high in entrepreneurial $(\mathrm{E})$, professional $(\mathrm{P})$ and leadership $(\mathrm{L})$ career mindset in order to cope with the work challenges of today.

\subsection{Personality and EPL Self-Efficacy}

The theoretical proposition of CSM argues that personality predicts self-efficacy. Self-efficacy is the subjective confidence that an individual has about his/her perceived ability to perform an action or complete a process. In the context of EPL, this means that the individual has the confidence to be concurrently high in entrepreneurial, professional, and leadership self-efficacy. Many types of researches in vocational studies (e.g., Ireland \& Lent, 2018; Lim, Lent, \& Penn, 2016) and entrepreneurship (e.g., Fuller, Liu, Bajaba, Marler, \& Pratt, 2018; Prabhu, McGuire, Drost, \& Kwong, 2012) have found personality to predict self-efficacy. Within the context of EPL, Chan, Uy, Chan., Uy, Chernyshenko, Ho, and Sam (2015) investigated the relationship between personality and EPL motivation. However, there has not been an empirical investigation on the role of personality on EPL self-efficacy.

Thus, studies examining the personality trait (extraversion, agreeableness, conscientiousness, neuroticism and openness) that leads to high EPL self-efficacy is lacking. Brandstätter (2011) showed extraversion, conscientiousness and openness to be relevant to entrepreneurship. Therefore, this study proposes that these traits should positively predict entrepreneurial self-efficacy. Also, we expect that these traits will positively influence leadership self-efficacy. This is premised on the high relationship that has been found (Butler, 2017; Felix, Aparicio, \& Urbano, 2019) between entrepreneurship and leadership. Furthermore, Chan et al. (2015) found a positive correlation between personality traits and entrepreneurial and leadership aspects of EPL motivation. On the professional aspect of EPL self-efficacy, we argue that the traits mentioned above will also be high on professional efficacy. This is because all of the participants sampled for the study were graduates, so, they should have professional efficacy to perform in their area of specialization.

Hypothesis 1: Extraversion, conscientiousness, and openness will lead to concurrently high EPL self-efficacy, whereas, those high in neuroticism and agreeableness will be high on professional self-efficacy. 


\subsection{Personality, Job and Entrepreneurial Outcome Expectations}

Outcome expectation is the beliefs about the consequences of performing an action. Self-efficacy is about "Can I do it", whereas, outcome expectation is about "What will happen if I do it". CSM theory identifies different types of outcome expectations: social (e.g., benefits to my family), material benefits (e.g. monetary gains) or self-evaluative (e.g., self-approval) outcome expectations. Lanero, Vázquez, and Aza (2016) also identified two types of outcome expectations, which are: internal or external outcome expectations. In the context of this study, we have two outcome expectations, which are: job (JOE) and entrepreneurial outcome expectations (EOE). JOE asks the question: "what will happen if I get a good job". Similarly, EOE is about: "what will happen if I venture into my own business".

CSM theory did not propose a direct path from personality to outcome expectations. However, recent empirical studies (Brown \& Cinamon, 2015, 2016) have shown a direct path from personality to outcome expectations. In this study, we argue that just as personality determines who has self-efficacy for a particular action, it also should determine the belief about the consequences of an action. Personality has been proven to influence career choice (Rogers, Creed, \& Glendon, 2008). People get attracted to careers whose expected outcomes are valued. For instance, open individuals should like the consequences of being a professional and an entrepreneur because their personality allows for receptiveness to different options. Conscientious individuals are achievement-driven. Achievement motivation is a core aspect of entrepreneurial pursuit; therefore, we proposed that conscientious people will score higher on EOE. Also, conscientious people are planful, think carefully before acting, and accept traditional norms. These characteristics are oriented towards a more traditional career. Thus, we argue that those high on conscientious personality will also be high on JOE. Extraverted people are assertive, dominant energetic and outgoing people. These characteristics are also useful for entrepreneurial careers than salaried jobs. So, high extraverted individuals should more incline towards EOE than JOE. Agreeable individuals are cooperative, loving, less self-centred. Therefore, agreeable individuals should be inclined towards JOE than EOE. Finally, neuroticism has to do with negative emotions towards a particular task. Therefore, individuals high in neuroticism should score low on both EOE and JOE.

Hypothesis 2: Extraversion, conscientiousness and openness will lead to high EOE and JOE, whereas, neuroticism and agreeableness will lead to only high JOE.

\subsection{EPL Self-Efficacy, Job and Entrepreneurial Outcome Expectations}

Self-efficacy has been both theoretically and empirically proven to influence outcome expectations. EPL selfefficacy should influence corresponding outcome expectation (Lent \& Brown, 2006). That is, entrepreneurial selfefficacy aspect of EPL should influence a corresponding EOE; professional self-efficacy influences a corresponding JOE. Lastly, leadership self-efficacy should influence both EOE and JOE because outcome expectations associated with leadership can be found both as a business owner and as a manager in an organization.

Hypothesis 3: Entrepreneurial and professional self-efficacy should lead to its corresponding outcome expectation, but leadership self-efficacy should lead to both types of outcome expectations.

\section{Methods}

\subsection{Study Participants}

Participants were 363 National Youth Service Corps (NYSC) members, selected from three cities (Abuja, Kano, and Ado-Ekiti) in Nigeria. We collected data in a paper and pencil format after developing a rapport with the participants. One hundred and ninety-one $(52.6 \%)$ were male, and one hundred and seventy-two (47.4\%) were females. Their age ranged from 19 to 39 . The mean age is 25.82, and the SD is 3.08. Yoruba ethnic group was $26.7 \%$, Igbo was $16.5 \%$, Hausa $36.4 \%$, and the South-south was $20.4 \%$. The number of Christians was $79.6 \%$, and Muslims were $20.4 \%$.

\subsection{Research Instruments}

We used four research instruments in this study. They are EPL self-efficacy, EOE, JOE, and personality scales.

EPL self-efficacy. This was measured with the scale developed by Chan et al. (2012). This was a 19-item scale measured on a 5-point Likert scale with endpoints of not at all confident to extremely confident. Sample items include: "Come up with ideas for products and services that may be needed in a market" (entrepreneurial self-efficacy); "Become one of the best experts or professionals in my field of specialization" (professional self-efficacy); and "Motivate others working with me to do more than they dreamed that could do" (leadership self-efficacy). The three dimensions of EPL self-efficacy have Cronbach's alpha that ranged from .84 to .88. As for validity, Chan et al. (2012) subjected the scale to both exploratory (EFA) and confirmatory factor analysis (CFA). The fit indices for this include a Comparative Fit Index (CFI) that ranged from .90 to .91 and Standardized Root Mean Square Residual (SRMR) that ranged from .04 to .05 for each factor.

JOE. This was measured with Kolvereid (1996) scale. We rewrote the scale's instructions to capture job outcome expectations. The revised instruction reads: "If I found a good job, I expect the following things will happen..." like it was done in other measures of outcome expectations (e.g., Lent, Ezeofor, Morrison, Penn, \& Ireland, 2016) Change of scales instructions have been done by other researchers such as Lim et al. (2016). It was an 11-item scale, measured on a 5-point Likert scale from 1 "strongly disagree" to 5 "strongly agree". The scale was found to be reliable with the subscales ranging from .68 to .90 . Also, from the data collected for this study, the scale reported a Cronbach's Alpha of .81.

EOE. This was measured with a scale developed by Lanero, Vázquez, and Aza (2015). They developed two subscales (namely: extrinsic and intrinsic) for entrepreneurial outcome expectation. For this study; however, the subscales were collapsed into one single measure of entrepreneurial outcome expectation. Altogether, the scale is a 14-item scale measured on a Likert scale from 1 "strongly disagree" to 5 "strongly agree". The scale has a reliability coefficient of .92, and convergent validity was calculated using Average Variance Extracted (AVE), and it 
ranged from .64 to .70 for the subscales. Sample items include: "good economic compensation"; "the chance to perform challenging and interesting work".

Personality. Personality was measured by the Big Five Inventory (BFI) developed by John and Srivastava (1999). Lent et al. (2016) found this scale to be very appropriate for career-related issues. It is a 44-item scale. It comprises five subscales (extraversion, agreeableness, conscientiousness, neuroticism, and openness to experience). Extraversion subscale consists of eight items. Sample item includes: "I see myself as someone who generates a lot of enthusiasm". Agreeableness consists of nine items. Sample item includes: "I see myself as someone who is helpful and unselfish with others". Conscientiousness has nine items, and a sample item is: "I see myself as someone who makes plans and follows through with them". Neuroticism has eight items, and sample item includes: "I see myself as someone who gets nervous easily". Finally, openness has ten items. Sample item includes: "I see myself as someone who is curious about many different things". Cronbach's alpha for the scale ranged from .79 to .88. For validity, John and Srivastava reported convergent validity for the five factors that ranged from .83 to .97

\section{Results}

The descriptive statistics comprising of mean and standard deviation with the zero-order correlations of the variables in this study are presented in Table 1. Looking Table 1, apart from neuroticism that is not significantly correlated with job $(r=-.09, p>.05)$ and entrepreneurial $(r=-.07, p>.05)$ outcome expectation, all the other variables of this study are positively correlated with each other.

Table-1. Mean scores, standard deviations, and inter-correlations between the variable entered into the model.

\begin{tabular}{|c|c|c|c|c|c|c|c|c|c|c|c|}
\hline Variable & Mean & SD & & & & & & & & & \\
\hline Extraversion & 1.05 & .27 & - & & & & & & & & \\
\hline Agreeableness & 2.68 & .48 & $.66^{* * *}$ & - & & & & & & & \\
\hline Conscientiousness & 1.50 & .25 & $.54 * *$ & $.67 * *$ & - & & & & & & \\
\hline Neuroticism & 21.93 & 4.29 & -.09 & $-.22 * *$ & $-.35^{* *}$ & - & & & & & \\
\hline Openness & 35.33 & 4.08 & $.57 * *$ & $.54^{* *}$ & $.47 * *$ & $-.18 * *$ & - & & & & \\
\hline Entrepreneurship SE & 3.45 & .72 & $.37 * *$ & $.38 * *$ & $.28 * *$ & $-.13^{*}$ & $.33^{* *}$ & - & & & \\
\hline Professional SE & 3.75 & .70 & $.43^{* *}$ & $.49^{* *}$ & $.43^{*} *$ & $-.27 * *$ & $.42^{* *}$ & $.75^{* *}$ & - & & \\
\hline Leadership SE & 3.80 & .71 & $.45^{* *}$ & $.48 * *$ & $.42 * *$ & $-.25 * *$ & $.40 * *$ & $.83^{* *}$ & $.92^{* *}$ & - & \\
\hline JOE & 43.46 & 6.58 & $.36^{* * *}$ & $.35 * *$ & $.26^{* *}$ & .09 & $.31 * *$ & $.31 * *$ & $.32 * *$ & $.32 * *$ & - \\
\hline $\mathrm{EOE}$ & 60.04 & 8.57 & $.51 * *$ & $.55^{* *}$ & $.49^{* *}$ & -.07 & $.40 * *$ & $.43^{*} *$ & $.50^{* * *}$ & $.51 * *$ & $.55 * *$ \\
\hline
\end{tabular}

Note: $\mathrm{SE}=$ self-efficacy, $\mathrm{EOE}=$ entrepreneurial outcome expectation, $\mathrm{JOE}=$ job outcome expectation, ${ }^{*} p \leq .05,{ }^{*} * \leq .01$.

\subsection{Hypotheses Testing}

We used a regression path analysis to test the hypotheses raised in this study, using analysis of moment structure (AMOS) version 23. For the hypothesized model, scholars (e.g., Iacobucci, 2010; Worthington \& Whittaker, 2006) are unanimous about the importance of fit statistics for any hypothesized model. This model showed a chi-squared value of $\chi_{(14)}^{2}=.632, p=.655$; Comparative fit index (CFI) value of 1.0; root mean square error of approximation (RMSEA) of .000; closeness of fit (PCLOSE) $=.98$ and; standardized root mean square residual $(\mathrm{SRMR})=.02$. All these fit statistics meet the standard values of a good statistical model.

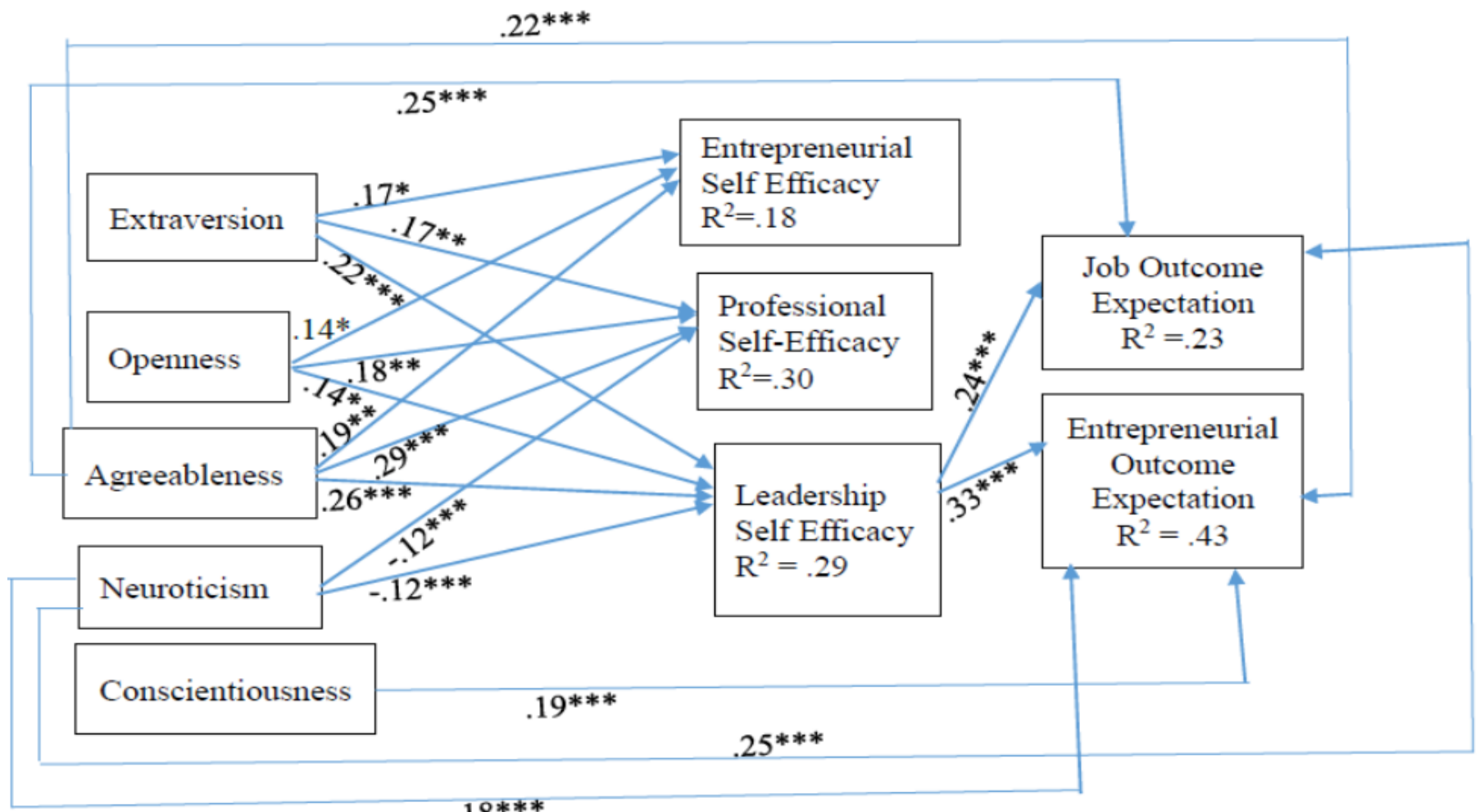

$.18^{*}$

Figure-1. The relationship between personality EPL self-efficacies and outcome expectations. $* p \leq .05, * * p \leq .01, * * * p \leq .001$.

Looking at Table 2 and Figure 1, the result of hypothesis one was partly supported. Extraversion led to high entrepreneurial $(\beta=.17, \mathrm{p}<.05)$, professional $(\beta=.17, \mathrm{p}<.01)$ and leadership $(\beta=.22, \mathrm{p}<.001)$ self-efficacy. Openness also led to high entrepreneurial $(\beta=.14, \mathrm{p}<.05)$, professional $(\beta=.18, \mathrm{p}<.001)$ and leadership $(\beta=.14$, 
$\mathrm{p}<.05)$ self-efficacies. Contrary to our hypothesis, agreeableness contributed to entrepreneurial $(\beta=.19, \mathrm{p}<.01)$, professional $(\beta=.29, \mathrm{p}<.001)$ and leadership $(\beta=.26, \mathrm{p}<.001)$ self-efficacy. Conscientiousness surprisingly however, did not significantly influence any of the self-efficacies. Lastly, neuroticism negatively related to professional $(\beta=-.12, \mathrm{p}<.001)$ and leadership $(\beta=-.12, \mathrm{p}<.001)$ self-efficacies.

For hypothesis two, none of our hypothesized models led to EOE and JOE. Conscientiousness, however, led to a significant $\operatorname{EOE}(\beta=.19, \mathrm{p}<.001)$, as shown in Table 2 and Figure 1. Therefore, (except for the conscientiousness that was partially supported), our alternate hypothesis is rejected. Neuroticism also significantly related with $\operatorname{EOE}(\beta=.25, \mathrm{p}<.001)$ and $\operatorname{JOE}(\beta=.18, \mathrm{p}<.001)$

Table-2. Results of the significant paths in the model.

\begin{tabular}{l|c|c|c|c}
\hline Hypothesized paths & $\boldsymbol{\beta}$ & $\mathbf{B}$ & SE $(\mathbf{B})$ & P \\
\hline Openness $\rightarrow$ Leadership SE & .14 & .024 & .010 & $<.05$ \\
\hline Extraversion $\rightarrow$ Leadership SE & .22 & .573 & .163 & $<.001$ \\
\hline Agreeableness $\rightarrow$ Leadership SE & .26 & .391 & .091 & $<.001$ \\
\hline Neuroticism $\rightarrow$ Leadership SE & -.12 & -.128 & .029 & $<.001$ \\
\hline Openness $\rightarrow$ Entrepreneurial SE & .14 & .024 & .011 & $<.05$ \\
\hline Openness $\rightarrow$ Professional SE & .18 & .030 & .010 & .001 \\
\hline Leadership SE $\rightarrow$ JOE & .24 & 2.258 & .497 & $<.001$ \\
\hline Extraversion $\rightarrow$ Entrepreneurial SE & .17 & .436 & .176 & $<.05$ \\
\hline Extraversion $\rightarrow$ Professional SE & .17 & .435 & .160 & $<.01$ \\
\hline Agreeableness $\rightarrow$ Entrepreneurial SE & .19 & .289 & .099 & $<.01$ \\
\hline Agreeableness $\rightarrow$ Professional SE & .29 & .416 & .089 & $<.001$ \\
\hline Agreeableness $\rightarrow$ JOE & .22 & 3.077 & .734 & $<.001$ \\
\hline Agreeableness $\rightarrow$ EOE & .25 & 4.521 & 1.005 & $<.001$ \\
\hline Conscientiousness $\rightarrow$ EOE & .19 & 6.558 & 1.755 & $<.001$ \\
\hline Neuroticism $\rightarrow$ Professional SE & -.12 & -.123 & .034 & $<.001$ \\
\hline Neuroticism $\rightarrow$ JOE & .25 & 2.394 & .457 & $<.001$ \\
\hline Neuroticism $\rightarrow$ EOE & .18 & 2.229 & .514 & $<.001$ \\
\hline Leadership SE $\rightarrow$ EOE & .33 & 4.045 & .554 & $<.001$ \\
\hline Note: SE $\rightarrow$ self-efficacy EOE $\rightarrow$ entrepreneuri &
\end{tabular}

Note: $\mathrm{SE}=$ self-efficacy, $\mathrm{EOE}$ = entrepreneurial outcome expectations, JOE = job outcome expectations

The result of hypothesis three, as presented in Table 2 and Figure 1, is also partially supported. Contrary to our predictions, entrepreneurial and professional self-efficacy did not influence their corresponding outcome expectations. However, in consonance with our hypothesis, leadership self-efficacy led to job $(\beta=.24, \mathrm{p}<.001)$ and entrepreneurial outcome expectations $(\beta=.33, \mathrm{p}<.001)$.

Finally, as presented in Figure 1, extraversion, openness, and agreeableness contributed $18 \%\left(\mathrm{R}^{2}=.18\right)$ of the variance in entrepreneurial self-efficacy. Extraversion, openness, agreeableness, and neuroticism contributed $30 \%$ $\left(\mathrm{R}^{2}=.30\right)$ of the variance in professional and $29 \%\left(\mathrm{R}^{2}=.29\right)$ of the variance in leadership self-efficacies.

\section{Discussion}

The result of hypothesis one supported the theoretical propositions of Lent and Brown (2013) about the relationship between personality traits and self-efficacy. There are some points to highlight from this result. First, past studies (e.g., Antoncic, Bratkovic Kregar, Singh, \& DeNoble, 2015; Kerr, Kerr, \& Xu, 2018) have found business founders to be low on agreeableness personality, this study, however, found that agreeable people are high in entrepreneurial self-efficacy. The explanation for this could be that, since self-efficacy is subjective confidence to achieve a purpose, agreeable people tend to agree with others that they have self-efficacy to be an entrepreneur. The same argument applies to their positive relationship with professional self-efficacy. Educated agreeable people may also be quick to assume they have the confidence (i.e. self-efficacy) to be a professional. Lastly, on the positive relationship between agreeableness and leadership self-efficacy, leadership, on the surface, is about relationships. Agreeable people may have the confidence to be a leader because they are good at working together with people. Another point to highlight in hypothesis one is the non-significant relationship between conscientiousness and the self-efficacies in this study. Unlike past researches that found conscientiousness as an essential predictor of entrepreneurial (e.g., Zhao \& Seibert, 2006) or vocational (e.g., Brown \& Hirschi, 2013; Lent et al., 2016) selfefficacy, this study found that conscientiousness did not relate with any of the self-efficacies investigated in this study. Antoncic et al. (2015) also find that conscientiousness did not relate to entrepreneurial intention and behaviour. More specifically, Chan et al. (2015) corroborated the result of hypothesis one by showing that conscientiousness performed poorly with respect to entrepreneurial and professional motivation. Neuroticism, as shown in the result of hypothesis one was negatively related with both professional and leadership self-efficacies. This result also corroborated the report of many studies (e.g., Hartman \& Betz, 2007; Nauta, 2004; Schaub \& Tokar, 2005; Spurk \& Abele, 2011) that also showed that neuroticism negatively related with self-efficacy.

The result of hypothesis two showed that only conscientiousness and neuroticism related to both EOE and JOE. Studies relating personality to outcome expectations are scarce. But the few ones available, such as Brown and Cinamon (2015) and Chan et al. (2015) also supported our result by showing that conscientiousness and neuroticism related to outcome expectations. This result also partly supported the theoretical proposition of Tran and Von Korflesch (2016) about the direct influence of personality traits on outcome expectation.

The result of hypothesis three countered the theoretical proposition of Lent and Brown (2013) by showing in hypothesis three that entrepreneurial and professional self-efficacies did not significantly relate with their corresponding outcome expectations. Leadership self-efficacy related, however, with both outcome expectations. The reason for this result may be the fact that leadership self-efficacy is needed in both entrepreneurial and salaried 
jobs. Therefore, individuals high in leadership self-efficacy may find outcome expectations associated with entrepreneurial and job outcome expectations appealing.

\section{References}

Antoncic, B., Bratkovic Kregar, T., Singh, G., \& DeNoble, A. F. (2015). The big five personality-entrepreneurship relationship: Evidence from Slovenia. Journal of Small Business Management, 53(3), 819-841. Available at: https://doi.org/10.1111/jsbm.12089.

Brandstätter, H. (2011). Personality aspects of entrepreneurship: A look at five meta-analyses. Personality and Individual Differences, 51(3), 222-230. Available at: https://doi.org/10.1016/j.paid.2010.07.007.

Brown, D., \& Cinamon, R. G. (2015). Personality traits' effects on self-efficacy and outcome expectations for high school major choice. International Journal for Educational and Vocational Guidance, 16(3), 343-361. Available at: https://doi.org/10.1007/s10775-015$9316-4$.

Brown, D., \& Cinamon, R. G. (2016). Contribution of personality to self-efficacy and outcome expectations in selecting a high school major among adolescents with learning disabilities. Career Development And Transition For Exceptional Individuals, 39(4), $237-248$. Available at: https://doi.org/10.1177/2165143415587689.

Brown, S. D., \& Hirschi, A. (2013). Personality, career development, and occupational attainment. In S. D. Brown \& R. W. Lent (Eds.), career development and counseling: Putting theory and research to work (2nd ed., pp. 299-328). New York: Wiley.

Butler, T. (2017). Hiring an entrepreneurial leader. Harvard Business Review, 95(2), 85-93.

Chan, K. Y., Moon-ho, R. H., Chernyshenko, O. S., Bedford, O., Uy, M. A., Gomulya, D., . . . Phan, W. M. J. (2012). Entrepreneurship, professionalism, leadership: A framework and measure for understanding boundaryless careers. Journal of Vocational Behavior, 81(1), 73-88. Available at: https://doi.org/10.1016/j.jvb.2012.05.001.

Chan, K.-Y., Uy, M. A., Chernyshenko, O. S., Ho, M.-H. R., \& Sam, Y.-L. (2015). Personality and entrepreneurial, professional and leadership motivations. Personality and Individual Differences, 77, 161-166. Available at: https://doi.org/10.1016/j.paid.2014.12.063.

Felix, C., Aparicio, S., \& Urbano, D. (2019). Leadership as a driver of entrepreneurship: An international exploratory study. Journal of Small Business and Enterprise Development, 26(3), 397-420. Available at: https://doi.org/10.1108/jsbed-03-2018-0106.

Frese, M., Gielnik, M. M., \& Mensmann, M. (2016). Psychological training for entrepreneurs to take action: Contributing to poverty reduction in developing countries. Current Directions in Psychological Science, 25(3), 196-202. Available at: https://doi.org/10.1177/0963721416636957.

Fuller, B., Liu, Y., Bajaba, S., Marler, L. E., \& Pratt, J. (2018). Examining how the personality, self-efficacy, and anticipatory cognitions of potential entrepreneurs shape their entrepreneurial intentions. Personality and Individual Differences, 125, 120-125. Available at: https://doi.org/10.1016/j.paid.2018.01.005.

Hartman, R. O., \& Betz, N. E. (2007). The five-factor model and career self-efficacy: General and domain-specific relationships. Journal of Career Assessment, 15(2), 145-161. Available at: https://doi.org/10.1177/1069072706298011.

Iacobucci, D. (2010). Structural equations modeling: Fit indices, sample size, and advanced topics. Journal of Consumer Psychology, 20(1), 9098 .

Ireland, G. W., \& Lent, R. W. (2018). Career exploration and decision-making learning experiences: A test of the career self-management model. Journal of Vocational Behavior, 106, 37-47. Available at: https://doi.org/10.1016/j.jvb.2017.1 1.004.

John, O. P., \& Srivastava, S. (1999). The big-five trait taxonomy: History, measurement, and theoretical perspectives. In L. Pervin, \& O. P. John (Eds.), handbook of personality: Theory and research (2nd ed., pp. $102-138)$. New York: Guilford.

Kerr, S. P., Kerr, W. R., \& Xu, T. (2018). Personality traits of entrepreneurs: A review of recent literature. Foundations and Trends $\mathbb{R}$ in Entrepreneurship, 14(3), 279-356. Available at: https://doi.org/10.1561/0300000080.

Kolvereid, L. (1996). Prediction of employment status choice intentions. Entrepreneurship Theory and Practice, 21(1), 47-58. Available at: https://doi.org/10.1177/104225879602100104

Lanero, A., Vázquez, J.-L., \& Aza, C. L. (2016). Social cognitive determinants of entrepreneurial career choice in university students. International Small Business Journal, 34(8), 1053-1075. Available at: https://doi.org/10.1177/0266242615612882.

Lanero, A., Vázquez, J. L., \& Aza, C. L. (2015). Social cognitive determinants of entrepreneurial career choice in university students. International Small Business Journal: Researching Entrepreneurship, 34(8), 1053-1075. Available at: https://doi.org/10.1177/0266242615612882.

Lent, R. W., Brown, S. D., \& Hackett, G. (1994). Toward a unifying social cognitive theory of career and academic interest, choice, and performance monograph. Journal of Vocational Behavior, 45, 79-122. Available at: https://doi.org/10.1006/jvbe.1994.1027.

Lent, R. W., \& Brown, S. D. (2006). On conceptualizing and assessing social cognitive constructs in career research: A measurement guide. Journal of Career Assessment, 14(1), 12-35. Available at: https://doi.org/10.1177/1069072705281364.

Lent, R. W., Ezeofor, I., Morrison, M. A., Penn, L. T., \& Ireland, G. W. (2016). Applying the social cognitive model of career selfmanagement to career exploration and decision-making. Journal of Vocational Behavior, 100(93), 47-57. Available at: https://doi.org/10.1016/j.jvb.2015.12.007.

Lent, R. W., \& Brown, S. D. (2013). Social cognitive model of career self-management: Toward a unifying view of adaptive career behavior across the life span. Journal of Counseling Psychology, 60(4), 557-568. Available at: https://doi.org/10.1037/a0033446.

Lim, R. H., Lent, R. W., \& Penn, L. T. (2016). Prediction of job search intentions and behaviors: Testing the social cognitive model of career self-management. Journal of Counseling Psychology, 63(5), 594-603. Available at: https://doi.org/10.1037/cou0000154.

Nauta, M. M. (2004). Self-efficacy as a mediator of the relationships between personality factors and career interests. Journal of Career Assessment, 12(4), 381-394. Available at: https://doi.org/10.1177/1069072704266653.

Prabhu, V. P., McGuire, S. J., Drost, E. A., \& Kwong, K. K. (2012). Proactive personality and entrepreneurial intent. International Journal of Entrepreneurial Behavior \& Research, 18(5), 559-586. Available at: https://doi.org/10.1 108/13552551211253937.

Rogers, M. E., Creed, P. A., \& Glendon, A. I. (2008). The role of personality in adolescent career planning and exploration: A social cognitive perspective. Journal of Vocational Behavior, 73(1), 132-142. Available at: https://doi.org/10.1016/j.jvb.2008.02.002.

Savickas, M. L. (2013). Career construction theory and practice. In S. D. Brown \& R. W. Lent (Eds.), career development and counseling: Putting theory and research into work (2nd ed.). Hoboken, NJ: John Wiley \& Sons.

Schaub, M., \& Tokar, D. M. (2005). The role of personality and learning experiences in social cognitive career theory. Journal of Vocational Behavior, 66(2), 304-325. Available at: https://doi.org/10.1016/j.jvb.2004.09.005.

Sinclair, R. F. (2008). The first step toward a theory of the entrepreneurial career. Paper presented at the United States Association for Small Business and Entrepreneurship Conference. San Antonio, Texas.

Spurk, D., \& Abele, A. (2011). Who earns more and why? indirect personality influences on salary. Journal of Business \& Psychology, 26(2), 87103. Available at: https://doi.org/10.1007/s10869-010-9184-3.

Tran, A. T. P., \& Von Korflesch, H. (2016). A conceptual model of social entrepreneurial intention based on the social cognitive career theory. Asia Pacific Journal of Innovation and Entrepreneurship, 10(1), 17-38. Available at: https://doi.org/10.1108/apjie-12-2016007 .

Worthington, R. L., \& Whittaker, T. A. (2006). Scale development research: A content analysis and recommendations for best practices. The Counseling Psychologist, 34(6), 806-838. Available at: https://doi.org/10.1177/0011000006288127.

Zhao, H., \& Seibert, S. E. (2006). The big five personality dimensions and entrepreneurial status: A meta-analytical review. Journal of Applied Psychology, 91(2), 259-271. Available at: https://doi.org/10.1037/0021-9010.91.2.259.

Asian Online Journal Publishing Group is not responsible or answerable for any loss, damage or liability, etc. caused in relation to/arising out of the use of the content. Any queries should be directed to the corresponding author of the article. 